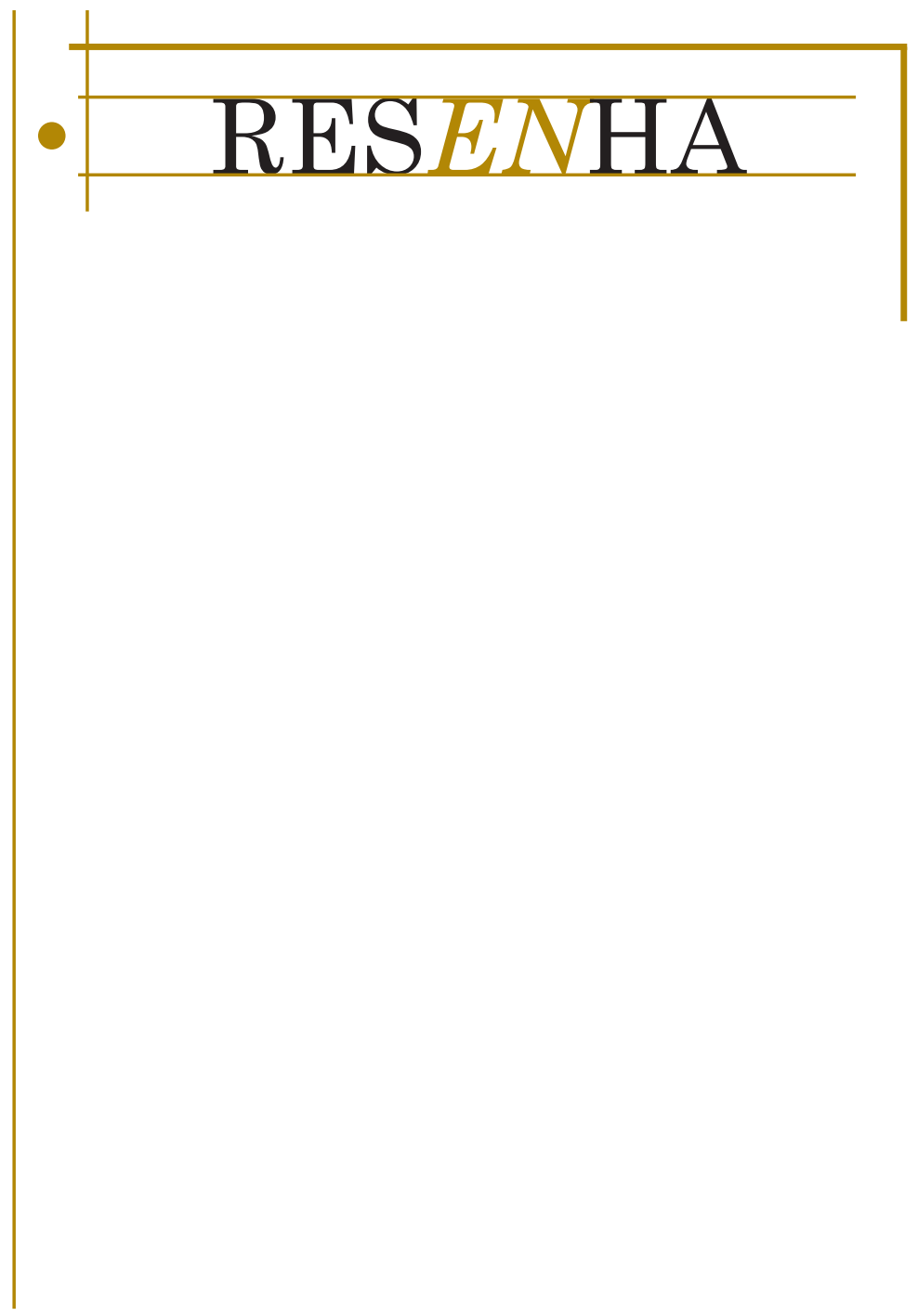




\section{CELEBRANDO AS MÚLTIPLAS IDENTIDADES}

Suany Oliveira de Moraes*

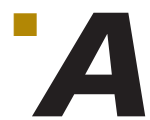

professora e pesquisadora Maria José Coracini, autora da obra $A$ celebração do outro, publicada pela primeira vez em 2007, é docente do Departamento de Linguística Aplicada do Instituto de Estudos da Linguagem na Universidade Estadual de Campinas(Unicamp) desde 1992, sendo livre-docente em Linguística Aplicada pela mesma instituição desde 2000.

A celebração do outro é composta por quatro capítulos, subdivididos em tópicos que, no seu conjunto, tratam de uma temática comum, a saber: a identidade, a memória discursiva e o interdiscurso. Essa obra é resultado de um minucioso e árduo trabalho de pesquisa voltado às problematizações do discurso, demarcadas por tensões (relações de poder-saber) e pelas contribuições teóricas de três renomados estudiosos: Foucault, Pêcheux e Derrida.

O corpus do trabalho de pesquisa da autora é constituído por variados gêneros textuais, em que variadas vozes "[...] provenientes de textos, de experiências, enfim, do outro, [...]se entrelaçam numa rede em que os fios se mesclam e se entretecem" (CORACINI, 2007, p. 9). Tem-se, na obra em questão, recortes de discursos tomados, ao mesmo tempo, como lugar de poder e de resistência nestes diferentes gêneros, quais sejam: entrevistas, recortes de jornal, redações de professores, histórias de vida e publicidade de escolas de linguas.

Na parte I da obra, intitulada "Da (Dis)Tensão Teórica", a autora, primeiramente, recorre às teorias de Lacan para tratar do sujeito da Análise do Discurso de linha francesa. Nesse primeiro momento, a professora afirma ser o sujeito construído pela alteridade, pela historicidade social e discursiva, que não controla o seu dizer, sendo, portanto, clivado, cindido, afetado pelo inconsciente. Assim, o sujeito constrói sua identidade, baseando-se no discurso de si e do outro. Depois, a autora dedica-se à discussão de duas importantes obras de

\footnotetext{
Universidade Federal de Mato Grosso do Sul (UFMS) - Três Lagoas - MS - Brasil. E-mail: suanymoraes@uol.com.br
} 
Pêcheux. Primeiro, retoma a obra inaugural da segunda fase da AD, A propósito de uma análise automática do discurso: atualizações e perspectivas, em que conceitos como formação social, lingua, discurso e ideologia são discutidos. Depois, discute noções como "ideologia dominada" e "desidentificação", tratadas na obra Discurso: estrutura ou acontecimento, na qual, com mais força, tem-se a heterogeneidade como princípio constitutivo do discurso e o equívoco como constitutivo da linguagem. Coracini fecha a primeira parte, considerando o monolinguismo como "o sonho da Torre de Babel". Temos a ilusão de que somos constituídos apenas pela nossa língua (a materna, em especial). Entretanto, a heterogeneidade constitui a linguagem e o sujeito. Nesse sentido, há um impedimento da delimitação das línguas, os sentidos não são transparentes, pelo contrário, são deslizantes e, por isso, Coracini (2007, p. 46) retoma Derrida ao tratar da "desconstrução" e da "impossibilidade da tradução como devolução do mesmo".

Na parte II do livro, "Da (im)possivel identidade do povo brasileiro", Coracini analisa as representações identitárias do brasileiro sobre o estrangeiro e sobre si mesmo, bem como as do estrangeiro sobre o Brasil e o brasileiro, em jornais e revistas de grande circulação. A autora problematiza tais construções de identidade que estão sempre em formação e cujo efeito de verdade é o que se tem materializado nos discursos estereotipados da sociedade: a cultura "superior" do estrangeiro versus a cultura indolente do brasileiro. Ainda nessa parte, Coracini traz discursos da/sobre a (in)submissão de mulheres que precisam ser transformados, pois elas ainda são vistas de um lugar desprestigiado, secundário na sociedade, apesar dos avanços de ordem socioeconômica e das políticas públicas de inclusão. Para concluir a segunda parte, a pesquisadora analisa textos de professores da rede estadual paulista, que participaram de um concurso, chamado "O professor escreve a sua história", no ano de 1996, cuja coletânea (alguns textos foram selecionados para publicação) recebeu o mesmo nome. Tem-se, aqui, o discurso da cidadania e da inserção social e as representações que atravessam o imaginário de professores e profissionais da educação sobre essas questões democráticas e neoliberais, tão condizentes com os discursos veiculados pelos Parâmetros Curriculares Nacionais (PCN).

A parte III de seu trabalho, intitulada "Ser/estar entre-línguas-culturas", a professora Coracini trata, inicialmente, da dicotomia lingua moderna (LM) e lingua estrangeira (LE) na constituição da subjetividade do sujeito "entre-línguas" e "entre-culturas". Foram analisadas seis entrevistas de adultos que passaram pela condição, pela experiência de sujeito-entre-línguas, e tal subjetividade é construída pelo espaço híbrido, pelo lugar do equivoco e pelo lugar do gozo, pela interdição e pelo lugar de repouso. Na sequência, Coracini problematiza a questão de a língua ser "materna" ou "madrasta", retomando Lacan, e a constituição do sujeito que, ao fazer uso da lingua, mais se diz do que diz, ou seja, ao tomar a palavra, o sujeito constitui-se discursivamente. Essa parte se fecha com a relação dicotômica entre a língua materna e a língua estrangeira: uma é a língua do saber e outra, a língua do conhecer; uma é a língua do conforto, e outra, do estranhamento. Ambas se entrelaçam, imbricam-se no momento histórico social.

$\mathrm{Na}$ quarta e última parte do livro, "Da identidade do tradutor e do professor de línguas", Coracini trata das configurações identitárias do sujeito tradutor, 
nos discursos sobre a tradução, como aquele que tem o desejo de controlar os efeitos de sentido, como aquele que deseja ser autor competente, mas que também se vê afetado pela cultura, pela ideologia, pelo equivoco da lingua que lhe causa "estranhamento". Em seguida, tal configuração identitária é reforçada nas representações do tradutor, em entrevistas publicadas na obra Conversas com tradutores (BENEDETTI; SOBRAL, 2003), em que o sujeito tradutor vive o conflito de ser fiel ao texto e ao autor e, paralelamente, a consciência da impossibilidade da perfeição, da falta, da lacuna. O sujeito tradutor é um sujeito que se reconhece como ponte do entre-línguas, mas também como traidor, sujeito da falta. Coracini segue a sua análise, problematizando questões identitárias relativas aos professores de lingua estrangeira e de profissionais que trabalham com a tradução no estado de São Paulo. Foram analisados relatos orais e questionários escritos desses profissionais de línguas, em que as relações entre teoria e prática são postas em discussão em discursos que se materializam pela dúvida, pelo medo de não atingir a perfeição e, consequentemente, pela divida.

A pesquisadora dá sequência em seu estudo, considerando as representações imaginárias do professor de língua na pós-modernidade frente ao uso das novas tecnologias. Tem-se, aqui, a configuração identitária de um sujeito fragilizado, de baixa estima, incompetente e resistente ao novo. A autora encerra o seu trabalho, analisando discursos publicitários de 15 escolas de línguas na capital de São Paulo, em Campinas e São José dos Campos. Em seu estudo, uma peça publicitária é inserida no sistema econômico neoliberal em que valores como economia de tempo e dinheiro, individualização (cursos personalizados) e metodologia avançada (salas multimídias) são repetidos com toda ênfase em detrimento da valorização do professor que é submetido a metodologias de ensino baseadas na tecnologia e no uso que se faz delas em sala de aula.

A celebração do outro é, sem dúvidas, uma obra indispensável não só para os professores de lingua materna e estrangeira, mas para qualquer leitor curioso de saber e conhecer mais a respeito das questões pertinentes à constituição das identidades de professores, tradutores, profissionais de lingua. Trata-se de obra de linguagem acessivel, que traz as considerações teóricas de Foucault, Pêcheux, Lacan e Derrida de maneira leve, mas nem por isso inconsistente. Muito pelo contrário, a autora mostra-se incansável na operacionalização de certos conceitos tão caros à Análise do Discurso e à Linguística Aplicada, tais como: ideologia, formações discursivas, interdiscurso, memória, identidade, sujeito, língua e linguagem. Certamente, esse trabalho, embora resultado de uma pesquisa publicada em 2007, é, ainda, atual (atemporal) e, nesse sentido, serve de referência para muitos estudos voltados à discursividade e às questões de identidade.

\section{REFERÊNCIAS}

BENEDETTI, I.; SOBRAL, A. (Org.). Conversas com tradutores: balanços e perspectivas da tradução. São Paulo: Parábola Editorial, 2003.

PÊCHEUX, M. Discurso: estrutura ou acontecimento? Tradução Eni Puccinelli Orlandi. Campinas: Pontes, 1990. 
PÊCHEUX, M.; FUCHS, C. A propósito de uma análise automática do discurso: atualizações e perspectivas. In: GADET, F.; HAK, T. Por uma análise automática do discurso. Campinas: Editora Unicamp, 1997. p. 61-162.

Recebido em dezembro de 2015. Aprovado em fevereiro de 2016.

\begin{tabular}{|r|r}
\cline { 2 - 2 } & CORACINI, Maria José. \\
\hline & A celebração do outro: arquivo, memória e identidade: \\
\hline & línguas (materna e estrangeira), \\
\hline & plurilinguismo e tradução. \\
\hline
\end{tabular}

